\title{
Inhibition of Fusarium causing death before life in sissoo (Dalbergia sissoo Roxb.)by a botanical-Putranjiva
}

\author{
Dr.Narendra Kumar \\ Bacteriology and Natural Pesticide Laboratory,Department of Botany,DDU Gorakhpur University, Gorakhpur-
} 273009

\begin{abstract}
Sissoo or sisham(Dalbergia sissoo Roxb.) is a medium to large-sized deciduous tree.The species occurs throughout the plains in north India,from Punjab to Assam ascending upto $100 \mathrm{~m}$ in the Himalayas.Due to the value of timber, sissoo is raised in plantations.During survey at 20 different places of four districts of Eastern U.P it has been found that in a one kilometer area if 100 plants of sisham are growing more than 30 plants has been found wilted.So frequent survey was conducted in order to collect wilted samples from 20 places of Eastern U.P districts. Survey of these places revealed that wilting occurs in all age groups, even in nursery plants, in age group of 10-15 year, 15-20 year,30-40 year,during humid months from July to September.In Basti district it was found highly alarming causing 50\% wilting in July months followed by Siddharth nagar, Santkabir nagar and Gorakhpur districtThe symptoms observed in all wilted plants were yellowing and death of leaves in acropetal succession and lastly entire plant in yellow appearance.So root samples were collected from wilted plants from these places for study of rhizoplane mycoflora. The root free from rhizosphere soil was cut into small pieces with the help of sterilized scalpel and forceps and plated on the medium and incubated at 20+_2C for 6 days to observe the appearance of fungi.Both sterilized and unsterilized root pieces were observed.In all age group Fusarium solani and Fusarium oxysporum were found to be present in both sterilized and unsterilized root pieces.Seven species of Fusarium isolated from roots were tested for their pathogenicity on sissoo.During pathogenicity testing of Fusarium solani,Fusarium oxysporum it was found that Fusarium solani is highly powerful causing $100 \%$ wilting in plants.

In nature plants are available which have volatile activity that can destroy fungal pathogens.So far 32 essential oils were extracted from higher plants and tested against Fusarium solani and Fusarium oxysporum. The oil of Putranjiva roxburghii showed complete inhibition of mycelia growth of both test fungi at 500ppm.The oil was thermostable at its mic of 500ppm and exhibited wide range of activity at 1000ppm.Moreover, the fungitoxicity was not destroyed by autoclaving and storage upto 120 days. The oil obtained from Feronia limonia also showed inhibitory activity at 1000ppm. The root and bark extract of Putranjiva was also found to be effective against both species of Fusarium.In this way this plant have overall anti action against Fusarium.So a little mixed field trial at nursery bed level was conducted with Putranjiva which showed no wilting symptoms compared with separately grown control sets of sissoo.So Putranjiva may be used against Fusarium to protect sissoo after successful large scale mixed plantation field trials.
\end{abstract}

\section{Introduction}

Sissoo or Shisham (Dalbergia sissoo Roxb) is a deciduous tree of family Papillionaceae and have great economic value. The species is found in India, Nepal, Bhutan, Bangladesh, Pakistan and Afghanistan. It is also found in tropical to subtropical Africa and Asia, viz. Java, Nigeria, Mauritius, Sri Lanka, Kenya, Northern Zimbabwe, Palestine and South Africa (Tewari, 1994). D. sissoo is an important fuel wood, shade, shelter and fodder tree. It usually cultivated in forest plantations and along the canals, roadsides, railway lines, water channels and borders of the agricultural fields.Plants of Sisham are at the verge of extinction no remedy is available for control.In North Eastern Uttar Pradesh a lot of sisham plants have been found wilted. Review of literature reveals that disease is caused by Fusarium solani (Mart) Wr. F.dalbergiae (Bagchee,1945;Bakshi,1954;Bakshi and Singh 1954,1959).Serious wilt of sissoo seedlings in nurseries caused by Fusarium oxysporum Fr. are reported from Pakistan(Browne,1968)

The number of diseases like powdery mildew, leaf rust, leaf blight, collar rot, wilt, die-back and Ganoderma root rot are reported by various research workers in Indo-Pakistan ( Bakshi, 1954,Khan,1989, Zakaullah, 1999,Khan and Khan,2000). Polyporus and Fusarium oxysporum cause root rot and wilt respectively (Khan, 1989). Fusarium solani was isolated as a facultative parasite associated with wounds and on hosts weekends by unfavorable conditions. Baral (1995) traced the first report of sissoo die back in the plantations of Nepal. A new form of disease die back has been established in sissoo. This disease has been reached epidemic proportion in Bangladesh and other countries of South Asia.25-30\% mortality was observed in Kasur,Pakistan(Khan et al.,2004). The heart wood of plant is strong and durable and have high timber quality so it needs protection.Elimination of pathogen from soil is not possible either chemically or by crop 
rotation(Bakshi,1955).Chemicals are pollutive in nature.Biocontrol agents are available which have their own limitations.In nature plants are available which have volatile activity that can destroy fungal pathogens.Now a days, essential oil and their components are gaining increasing interest because of relatively safe status,their wide acceptance by consumers and their exploitation for potential multipurpose functional use(Ormancey et al.,2001;Sawamura,2000;Kumar and Tripathi,2007).

Since no systematic work has been done in sisham wilting in north Eastern U.P so wilted samples were collected.Fungal organisms were isolated and pathogenicity tests were conducted and 32 essentials isolated from higher plants were evaluated.The fungitoxic properties of oil were studied and a little mixed field trial at nursery level was conducted in order to recommend most potent plant for protection of sisham after large scale field trials.

\section{Disease sample collection}

\section{Materials and Methods}

A thorough survey of sisham growing area of North Eastern U.P regions of districts viz.,Basti,Sant kabir nagar,Siddharthnagar, Gorakhpur and Maharajganj district places were carried out in humid months(July to September) from 1997 to 2008 to find the symptoms and severity of wilted plants of sisham. The natural diseased plants showing the typical symptoms of disease were selected from the field and samples of root portion of diseased sisham tree were collected for the isolation of associated pathogens.

\section{Places visited in districts of north Eastern U.P}

Basti-Ganeshpur,Kalwari,Makhauda,Chhawni Bazar,Walterganj in Santkabir nagar-Baghnagar,Mehdaul,Matiuli,Alinagar,Gagargarh, in Siddhartha nagar-Bansi,Itwa,Chandapar,Chilia,Birdpur inGorakhpur-Brhalganj,Golabazar,Kauriram,Kusmi,Pali in Maharajganj-Nautanwa,Sanduriya,Khucha,Paniyara,Nichlaul

These places were visited for collection of root samples for isolation of mycoflora and recording of $\%$ wilting and age group of plants by discussion with local people.The symptoms of wilted plants were studied.The root samples were kept in presterilized polyethylene bags after labeling the name of district and place.

\section{Isolation of pathogens from roots of infected sissoo plants}

Wilted sissoo plants collected during survey were brought to the laboratory and washed to remove adhering soil from roots. These were then sterilized by dipping in 0.5 per cent $\mathrm{NaOCl}$ (sodium hypochlorite) solution for 3-5 minutes. The root were then dried on paper towels and cut into pieces of $1 \mathrm{~cm}$ size.A vertical slit was made in each piece which were placed sperately in petridishes containing solidified potato dextrose agar(PDA) medium and incubated at $20 \pm 2{ }^{\circ} \mathrm{C}$ for six days to observe the appearance of fungi. The fungi thus appeared were purified by single hyphal tip culture technique and maintained on PDA slants. The fungi were identified by comparing their morphological and cultural characteristics with authentic culture maintained in the Mycology laboratory of my department as well as with help of literature(Gillman,1967;Booth,1971;Ellis,1971,1976).

Per cent occurance of each fungal species associated with root sample was calculated as per formulaPercent occurrence $=$ Number of colonies of a particular fungas/Total number of colonies of all the fungi X 100

\section{Pathogenicity}

The pathogenicity of all species of Fusarium on the host plant was evaluated.The isolates of Fusarium were grown on PDA in petriplates.Fungal discs of each species was taken from 7-day old culture and mixed with maizemeal and sterilized soil $(1 ; 1 ; 8 \mathrm{w} / \mathrm{w} / \mathrm{w}$ respectively).The soil thus inoculated was placed in earthen pots.Sterilized soil upto $2 \mathrm{~cm}$ height was again filled in the pots which were given light irrigation. The sick pots thus prepared were covered with parchment paper and incubated for 7 days in greenhouse before sowing.Control sets were prepared by using only sterilized soil mixed with maize meal $(9 ; 1 \mathrm{w} / \mathrm{w})$ without fungal inoculam. Seeds of sissoo were surface sreilized by dipping in 5 per cent $\mathrm{NaOCl}$ solution for 5 minutes.Five such seeds were sown in the top layer of sterilized soil of each pots. The pots were irrigated at regular intervals.Experiment was repeated twice,each containing 10 replicates and observation were recorded on $40^{\text {th }}$ day.

\section{Isolation of essential oils from higher plants}

The leaves of 32 higher plants collected separately from Gorakhpur locality were surface sterilized by dipping in $70 \%$ ethanol and then washed repeatedly with sterilized double distilled water.The surface sterilized 
leaves were macerated and hydrodistilled for isolation of volatile constituents separately for 6 hour in clevengers apparatus.After hydrodistillation immiscible oil was separated and dehydrated over anhydrous sodium sulphate separately to remove traces of moisture.

\section{Fungitoxicity testing}

The toxicity of oil was assessed by using the inverted petri plate technique of Bocher(1938). The fungitoxicity of essential oils was measured following Dixit et al.(1978) and recorded in terms of per cent inhibition of mycelial growth.

Determination of mic of most active oil

The mic of most active oil was determined by poisioned food technique of Grover and Moore(1962).Different concentration of the oil ranging from 200 to $600 \mathrm{ppm}$ were prepared by dissolving requsite amount of oil in $0.5 \mathrm{ml}$ acetone and then mixing with 9.5 mlczapeks dox agar medium eperately.In control sets the petriplates having acetone and medium without oil were used.Fungal discs $(5 \mathrm{~mm}$ diam $)$ abtained from periphery of seven $\mathrm{d}$ old culture of each of test fungi were aseptically inoculated in each of the treatment and control sets.All these sets were incubated at $28+-2 \mathrm{C}$ for 6 days.Diameters of fungal colony of treatment/control sets were measured in mutually perpendicular directions on the $7^{\text {th }} \mathrm{d}$ and the average was used to calculate the percent inhibition of mycelia growth of test fungi separately.The oil treated discs of the fungi showing complete inhibition of thir mycelia growth upto $7 \mathrm{~d}$ were washed with sterile water and placed again on fresh solidified medium to observe the revival of mycelia growth.The fungitoxic spectrum of the oil was studied against various fungi isolated from root samples.In addition effect of temperature ,autoclaving and storage on the fungitoxicity of oil was determined following Pandey et al(1982).Each experiment was repeated twice and contained 5 replicates.

\section{Fungitoxic studies in root and bark and seed extract of Putranjiva} Fusarium.

This was determined by poisioned food technique of Grover and Moore(1962) against both species of

\section{Mixed field trial with Prautnjiva plant}

For mixed field trial nursery bed of $1 \mathrm{mx} 1 \mathrm{~m}$ area( 5 such bed) were prepared at 6 inches above from the ground level.For mixed trial 100 seed of sissoo and 100 seed of Putranjiva were taken and kept in soil at each bed one after the other for growing and properly watering was done.For control set another bed of $1 \mathrm{mx} 1 \mathrm{~m}$ area was prepared at 6 inches above ground level and 200 seeds were sown.Both alone and treatment sets were kept under observation for 3 years.

\section{Botany of sisham}

\section{Results}

D. sissoo is a medium to large deciduous tree with a light crown which reproduces by seeds and suckers. It can grow up to a maximum of $25 \mathrm{~m}(82 \mathrm{ft})$ in height and 2 to $3 \mathrm{~m}(6 \mathrm{ft} 7 \mathrm{in}$ to $9 \mathrm{ft} 10 \mathrm{in})$ in diameter, but is usually smaller. Trunks are often crooked when grown in the open. Leaves are leathery, alternate, pinnately compound and about $15 \mathrm{~cm}$ (5.9 in) long. Flowers are whitish to pink, fragrant, nearly sessile, up to $1.5 \mathrm{~cm}$ (0.59 in) long and in dense clusters 5-10 cm (2.0-3.9 in) in length. Pods are oblong, flat, thin, strap-like 4-8 cm (1.6-3.1 in) long, $1 \mathrm{~cm}(0.39 \mathrm{in})$ wide and light brown. They contain 1-5 flat bean-shaped seeds $8-$ $10 \mathrm{~mm}(0.31-0.39 \mathrm{in})$ long. They have a long taproot and numerous surface roots which produce suckers. Young shoots are downy and drooping; established stems with light brown to dark gray bark to $2.5 \mathrm{~cm}$ (0.98 in) thick, shed in narrow strips; large upper branches support a spreading crown.

During survey more than $30 \%$ plants has been found wilted at 20 places of eastern U.P districts.It is evident fromTable1, that wilting is highly alarming in Basti district causing 50\%wilting in the month of July followed by Siddharthanagar,Santkabirnagar and Gorakhpur district.

As evident from Table2, wilted plants of sissoo were observed in all age groups,in nursery plants,in age group 5-10 year,10-15year,15-20year,30-40year which showed yellowing and death of leaves in acropetal sucession and lastly death of entire plant in humid months from July to September.

It is evident from Table3,that 16 fungal species were found to be associated with sterilized and unsterilized root pieces.The per cent occurrence of Fusarium oxysporum in Basti ,Santkabirnagar,Siddharthanagar,Gorakhpur district was found to be $80.3,80.1,78.5,53.2$ per cent respectively and that of Fusarium solani was 79.2,79.2,79.3 and54.4 per cent respectively.Other fungi showed lower or moderate percentage of occurrence.

It is evident from Table4,that during pathogenicity Fusarium oxysporum showed $90 \%$ wilting while Fusarium solani showed $100 \%$ wilting while control set showed no wilting symptoms.Except Fusarium oxysporum and Fusarium solani,none else exhibited wilting in more than $50 \%$ plants.Amongst Fusarium 
species,F.avenaceum exhibited different levels of pathogenicity on sissoo plants. On account of wide occurrence and their pathogenicity these were selected as test organisms.

The essential oil of Putranjiva roxburghii Wall exhibited absolute toxicity at 500ppm inhibiting mycelial growth of both test fungi completely,while other oils at these concentrations showed lower level of fungitoxicity(Table 5).

The MIC of the oil was found to be 500ppm against both the test fungi.The oil exhibited fungicidal nature at hyper MIC against both the test fungi(Table 6).

The broad range of fungitoxicity against different fungi was also found in the present study,confirming a broad fungitoxic spectrum. The sensitivity of different fungi also varies with the variation in concentration of oils(Table 7).

The essential oil of Putranjiva retained fungitoxic factor upto 120d,the maximum period taken into consideration(Table 8).

During present investigation the oil of Putranjiva was found to be fungistatic in nature at its MIC of $500 \mathrm{ppm}$ while it exhibited fungicidal nature of toxicity at higher concentration against both the test fungi viz.,Fusarium oxysporum and Fusarium solani.The oil was thermostable, retained absolute toxicity on autoclaving and storage upto $120 \mathrm{~d}$.Further the oil showed broad range of activity at 1000ppm

It is evident from Table9, the root, bark and seed extract of Putranjiva showed $100 \%$ mycelial inhibition of both test fungi at 1;10 dilution.This feature does not indicate the ineffectiveness in control of Fusarium because it has antiaction against both species and will reduce the population of Fusarium.

It is evident from Table 10,that a little mixed field trial at nursery level upto three year showed $25 \%$ wilting in control set when only sissoo plants were grown while in treatment set a mixed nusery preparation of sissoo and Putranjiva one after other showed complete protection of wilting symptoms.

\section{Discussion}

Bakshi(1954) reported that wilt disease of sisham in Dehradun and Saharanpur district of western Uttar Pradesh is due to Fusarium solani.In present investigation both Fusarium oxysporum and Fusarium solani are responsible for wilting.Bakshi(1954) mentioned that only trees of 15-25 year old suffer from this disease,but in present investigation even nursery plants have found suffering from wilting disease.Browne(1968) recorded serious wilt of sissoo seedlings in nurseries due to Fusarium oxysporum and Rosellina aquila from Pakistan.

The leaflets gradually turn yellow and eventually turn yellow and eventually drop off.The entire tree becomes thin and light coloured as observed by Bakshi(1954) have been also observed in present investigation.

According to Wellman(1967) a fungicide must retain its fungitoxicity at the extreme of temperatures.The fungitoxicity of the oil of Putranjiva was found to be thermostable upto 100C like Ageratum conyzoides(Dixit et al.,1995) and Nardostachys jatamansi(Mishra et al.,1995).The oil retained its fungitoxicity on autoclaving(15lbs/square inch pressure).This quality of oil will facilitate the isolation of their constituents in active state.

A fungicide should be able to retain its activity during long period of its storage(Wellman,1967).The fungitoxic factor in the oil of Adenocalyma allicea was lost within $21 \mathrm{~d}$ of storage(Chaturvedi,1979) while persisted for long period in the oil of Ageratum conyzoides(Dixit et al.,1995),Trachyspermum ammi(Singh and Tripathi,1999). The separately grown set of sissoo showed yellowing and death of leaves and ultimately death of entire plants.So in order to protect sissoo Putranjiva may be used against Fusarium after successful large scale mixed planation field trials. The monoculture concept for sissoo should be removed in order to conserve this plant because this at the stage of extinction.

The work done tells that root cause of wilting of sisham is species of Fusarium and for their management putranjiva which is also a tree have capacity for their protection so that there is a need of large scale mixed plantation trials.It is requested from forest department and farmers please do mixed plantation for protection of sisham.

\section{Acknowledgement}

Author is thankful to Head, Department of Botany for providing Laboratory facilities.

\section{References}

[1]. Bagchee,K.D(1945)Pathological notes, Wilt and dieback of Sisham,babul and khair in the artificial regeneration under agriculture cum forestory management.Indian Forester 71;20-24.

[2]. Bakshi,B.K and Singh,S(1959)Root disease of sisham.Indian Forester,85;415-421.

[3]. Bakshi,B.K(1954)Wilt of sisham(Dalbergia sissoo Roxb.) due to Fusarium solani Snyder and Hansen.Nature 174;278-279.

[4]. Bakshi,B.K(1955)Wilt disease of sisham,behavior of Fusarium solani the wilt organism in soil.Indian Forester 81;276-281.

[5]. Bocher,O.E(1938)Antibiotics.In;Modern methods of plant analysis.Eds.Peach K and Tracey M.V(ed.).Modern methods of plant analysis vol iii,651,Springer-Verlag,Berlin.

[6]. Both,C(1971) The genus Fusarium.CommonWealth Mycological Institute,Kew,Surrey,England. 
[7]. Browne F,G(1968)Pest and diseases of forest plantation trees.1330pp Clarendon Press,Oxford.

[8]. Chaturvedi,R(1979)Evaluation of higher plants for their fungitoxicity against Helminthosporium oryzae.Ph.D Thesis Gorakhpur Uniersity,Gorakhpur,India.

[9]. Dixit S.N.,Tripathi,N.N and Tripathi,S.C(1978)Fungitoxicity of some seed extracts .Nat.Acad.Sci.Letters 1;287-288.

[10]. Dixit,S.N.,Chandra,H.,Tiwari,R and Dixit,V(1995)Development of botanical fungicide against blue mould of mandarins.J.Stored Prod.Res.,31(2);165-172.

[11]. Ellis,M.B(1971)Dematiaceous hyphomycetes.Commonwealth Mycological Institute,Kew.Surrey,England.

[12]. Ellis,M.B(1976)More dematiaceous hyphomycetes.CommonwealthMycological Institute,Kew.Surrey,England

[13]. Grover R.K and Moore J.D(1962)Toximetric studies of fungicides against brown rot organism,Sclerotinia fructicola and S.laxa.Phytopath 52;876-880.

[14]. Gillman J.C(1967) A manual of soil fungi.Oxford and JBH publishing co. Calcutta.India.

[15]. Khan,H.S,Idrrees,M.,Mohmadd,F.Mahmood,A and Zaidi,S.H(2004)Incidence of sisham decline and invitro response of isolated fungus species to various fungicides.International Journal of Agriculture and Biology,6(4);611-614.

[16]. Kumar,N and Tripathi,N.N(2004)Repellent property of volatile oil isolated from Putranjiva roxburghii against Trogoderma granarium associated with stored groundnut seeds.Proc.Nat.Acad.Sci India 74B(11);179-187.

[17]. Mishra D.,Chaturvedi,R.V and Tripathi, S.C(1995The fungitoxic effect of the essential oil of the herb Nardostachys jatamansi D.C. Tropical Agri 72(1);48-52.

[18]. Muskett A.F(1948)Technique for the examination of seeds for the presence of seed borne fungi.Trans.Br.Mycol,30;74-83.

[19]. Ormancy,Y.,Sissali,S and Coutiere,P(2001)Formulation of essential oils in functional perfumery.Perfumes Cosmetiques, Actualities, 157;30-40.

[20]. Pandey, D.K ,Chandra,H and Tripathi,N.N(1982)Volatile fungitoxicity of some higher plants with special reference to that of Callistemon lanceolatus D.C.Phytopath Z 105; $175-182$.

[21]. Sawamura,M(2000)Aroma and functional properties of Japanese yuzu(Citrus junos Tanaka) essential oil.Aroma Research 1;14-19.

[22]. Singh,J and Tripathi,N.N(1999)Inhibition of storage fungi of black gram(Vigna mungo L) by some essential oils.Flavour Fragrance J. 14;1-4.

[23]. Wellman,R.H(1967)Commercial development of fungicides.In;Plant pathology Problem and Progress Eds Holtan et al.,19081958.Indian University Press,Allahabad, India.

Table1.Per cent wilting of sissoo at different places of eastern U.P in months of July

\begin{tabular}{|l|l|}
\hline Name of place & Per cent wilting \\
\hline Basti District & 50 \\
Ganeshpur & 54 \\
Kalwari & 59 \\
Makhauda & 50 \\
Chhawni Bazar & 54 \\
Walterganj & \\
\hline Santkabirnagar District & \\
Baghnagar & 30 \\
Mehndawl & 38 \\
Matiuli & 30 \\
Alinagar & 39 \\
Gagargarh & 37 \\
& \\
\hline Siddharthanagar & \\
Bansi & 41 \\
Itwa & 40 \\
Chandapur & 43 \\
Chilia & 40 \\
Birdpur & 48 \\
\hline Gorakhpur & 30 \\
Barhalganj & 30 \\
Golabazar & 31 \\
Kauriram & 32 \\
Kusmi & \\
\hline
\end{tabular}

Table 2.Symptoms observed in wilted plants of sissoo in different age groups

\begin{tabular}{|l|l|}
\hline Age group & Symptoms \\
\hline Nursery plants 1-2 years & Complete yellow \\
\hline $5-10$ year & Light yellow \\
\hline $10-15$ year & Upper half yellow in acropetal order \\
\hline $15-20$ year & yellow \\
\hline $30-40$ year & Complete yellow \\
\hline
\end{tabular}


Inhibition of Fusarium causing death before life in sissoo (Dalbergia sissoo Roxb.)by a botanical-

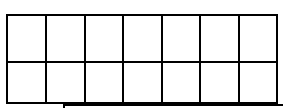

Fungal species

Absidia spinosa Lender

Acremonium album Cattaneo

Alternaria solani Keissler

A.niger Van Teighmer

A.tamari Kita

F.avenaceum Schl

F.chlamydosporum Wallen Welber

and Reinking

F.equseti(Corda)

Saccardo

F.moniliforme Schl

F.nivale Schl

Fusarium oxysporum $\mathrm{Schl}$

Humicola grises Omvik

Penicillium chrysogenum Thom

P.funiculosum Thom

P.oxalicum Currie and Thom
F.solani(Mart)Sacc

Table 3.Per cent occurrence of isolated fungi from rhizoplane of sissoo in different district

\begin{tabular}{|c|c|c|c|c|}
\hline & \multicolumn{4}{|c|}{ Average per centage of isolated fungi } \\
\hline & Basti & Santkabirnagar & Siddharthanagar & Gorakhpur \\
\hline & 1.0 & 1.0 & 2.0 & 2.1 \\
\hline 0 & 2.3 & 2.1 & 2.3 & 2.4 \\
\hline & 3.1 & 3.1 & 3.0 & 3.2 \\
\hline & 1.4 & 0.7 & 2.1 & 0.8 \\
\hline & 3.2 & 2.2 & 2.4 & 15.0 \\
\hline & 3.7 & 4.1 & 0.6 & 0.6 \\
\hline \multirow[t]{7}{*}{ n Welber } & 2.2 & 1.0 & 4.0 & 0.4 \\
\hline & 2.1 & 2.2 & 2.2 & 2.5 \\
\hline & 1.0 & 1.2 & 1.1 & 1.2 \\
\hline & 3.2 & 4.2 & 4.1 & 4.6 \\
\hline & 80.3 & 80.1 & 78.5 & 53.2 \\
\hline & 79.2 & 79.2 & 79.3 & 54.4 \\
\hline & 3.4 & 4.7 & 4.0 & 3.0 \\
\hline \multirow[t]{3}{*}{ hom } & 3.7 & 4.5 & 4.1 & 4.4 \\
\hline & 10.0 & 15.0 & 16.3 & 14.3 \\
\hline & 3.0 & 2.0 & 1.0 & 2.2 \\
\hline
\end{tabular}

Table 4.Fungal species vis-à-vis wilting of sissoo

\begin{tabular}{|l|l|}
\hline Fungal species & Per cent wilting \\
\hline F.avenaceum & 20.0 \\
\hline F.chlamydosporum & 2.0 \\
\hline F.equseti & 2.0 \\
\hline F.moniliforme & $\mathbf{8 . 0}$ \\
\hline F.nivale & 5.0 \\
\hline F.oxysporum & 90.0 \\
\hline F.solani & 100.0 \\
\hline
\end{tabular}

Table 5.Evaluation of essential oils of higher plants against Fusarium oxysporum and F.solani

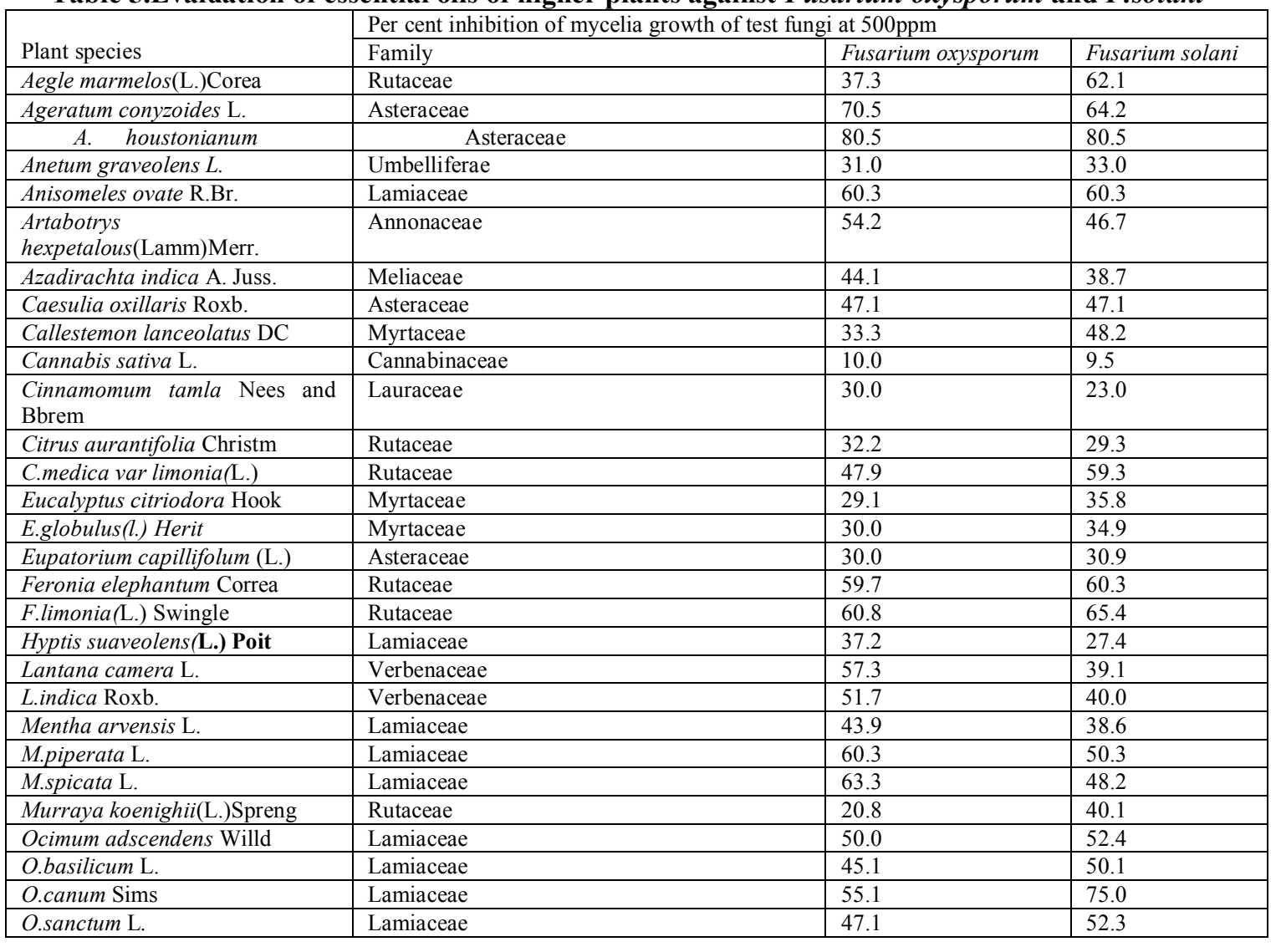


Inhibition of Fusarium causing death before life in sissoo (Dalbergia sissoo Roxb.) by a botanical-

\begin{tabular}{|l|l|l|l|}
\hline Putranjiva roxburghii Wall & Euphorbiaceae & 100 & 100 \\
\hline Tagetes erecta L. & Asteraceae & 40.0 & 30.7 \\
\hline Thuja occidentalis L. & Cuppressaceae & 23.0 & 46.3 \\
\hline
\end{tabular}

Table 6. MIC of the essential oil of Putranjiva roxburghii

\begin{tabular}{|l|l|l|}
\hline Dose of oil in ppm & Fusarium oxysporum & Fusarium solani \\
\hline 200 & 30 & 40 \\
\hline 300 & 40 & 40 \\
\hline 400 & 70 & 80 \\
\hline 500 & 100 & 100 \\
\hline 600 & $100^{*}$ & $100^{*}$ \\
\hline
\end{tabular}

*Fungicidal

Table 7.Fungitoxic spectrum of oil of Putranjiva roxburghii at sub lethal, lethal and hyperlethal doses

\begin{tabular}{|c|c|c|c|c|}
\hline \multirow[b]{2}{*}{ Fungal species } & \multicolumn{4}{|c|}{ Per cent inhibition of mycelial growth of isolated fungi } \\
\hline & $\begin{array}{l}\text { Subletha } \\
300 \mathrm{ppm}\end{array}$ & $\begin{array}{l}\text { Lethal } \\
500 \mathrm{ppm}\end{array}$ & $\begin{array}{l}\text { Hyperlethal } \\
700 \mathrm{ppm}\end{array}$ & $\begin{array}{l}\text { Hyperlethal } \\
1000 \text { ppm }\end{array}$ \\
\hline Absidia spinosa Lender & 45.6 & 80.0 & 100.0 & 100.0 \\
\hline Acremonium album Cattaneo & 49.6 & 89.0 & 100.0 & 100.0 \\
\hline Alternaria solani Keissler & 50.0 & 100.0 & 100.0 & 100.0 \\
\hline A.niger Van Teighmer & 49.0 & 100.0 & 100.0 & 100.0 \\
\hline A.tamari Kita & 60.0 & 100.0 & 100.0 & 100.0 \\
\hline F.avenaceum Schl & 68.0 & 100.0 & 100.0 & 100.0 \\
\hline $\begin{array}{l}\text { F.chlamydosporum Wallen Welber } \\
\text { and Reinking }\end{array}$ & 79.0 & 100.0 & 100.0 & 100.0 \\
\hline $\begin{array}{l}\text { F.equseti(Corda) } \\
\text { Saccardo }\end{array}$ & 65.6 & 100.0 & 100.0 & 100.0 \\
\hline F.moniliforme Schl & 68.6 & 100.0 & 100.0 & 100.0 \\
\hline F.nivale Schl & 68.6 & 79.6 & 100.0 & 100.0 \\
\hline Fusarium oxysporum Schl & 80.0 & 100.0 & 100.0 & 100.0 \\
\hline F.solani(Mart)Sacc & 79.0 & 100.0 & 100.0 & 100.0 \\
\hline Humicola grises Omvik & 74.0 & 100.0 & 100.0 & 100.0 \\
\hline Penicillium chrysogenum Thom & 75.0 & 80.0 & 90.0 & 100.0 \\
\hline P.funiculosum Thom & 75.9 & 95.0 & 100.0 & 100.0 \\
\hline P.oxalicum Currie and Thom & 74.6 & 95.6 & 98.6 & 100.0 \\
\hline
\end{tabular}

Table 8.Effect of physical factors on the fungitoxicity of Putranjiva roxburghii Wall

\begin{tabular}{|l|l|}
\hline Physical factors & $\begin{array}{l}\text { Per cent inhibition of mycelial } \\
\text { Growth at its MIC }\end{array}$ \\
\hline Temperature $\left({ }^{\circ} \mathrm{C}\right)$ & \\
Time of treatment-60min & 100 \\
$40^{\circ} \mathrm{C}$ & 100 \\
$60^{\circ} \mathrm{C}$ & 100 \\
$80^{\circ} \mathrm{C}$ & 100 \\
$100^{\circ} \mathrm{C}$ & 100 \\
\hline Autoclaving & \\
$(15 \mathrm{lbs} /$ sq inch pressure at $120 \mathrm{C})$ & \\
For 15 min & \\
\hline Storage in days & 100 \\
15 & 100 \\
30 & 100 \\
45 & 100 \\
60 & 100 \\
75 & 100 \\
90 & 100 \\
105 & 100 \\
120 & \\
\hline
\end{tabular}

Table 9.Evaluation of extracts of Putranjiva at 1;10 dilution against test fungiPer cent inhibition of mycelial growth

\begin{tabular}{|l|l|l|}
\hline Name of extract & Fusarium oxysporum & Fusarium solani \\
\hline Root extract & 100 & 100 \\
\hline Bark extract & 100 & 100 \\
\hline Seed extract & 100 & 100 \\
\hline
\end{tabular}


Inhibition of Fusarium causing death before life in sissoo (Dalbergia sissoo Roxb.) by a botanical-

Table 10.Observation of mixed trial with Putranjiva plant and sissoo plant upto three year

\begin{tabular}{|l|l|}
\hline $\begin{array}{l}\text { Control set } \\
\text { (only sissoo plant) }\end{array}$ & $\begin{array}{l}\text { Treatment set } \\
\text { (mixed nursery preparation with Putranjiva } \text { plant) } \\
\text { No wilting }\end{array}$ \\
\hline $\begin{array}{l}\text { Yellowing and death } \\
\text { of leaves and ultimately } \\
\text { death of entire plants }\end{array}$ & Plants found luxuriantly growing \\
\hline
\end{tabular}

